\title{
Erratum to: Uniform standards for genome databases in forest and fruit trees
}

\author{
J. L. Wegrzyn • D. Main • B. Figueroa $\cdot$ M. Choi $\cdot$ J. Yu • \\ D. B. Neale $\cdot$ S. Jung $\cdot$ T. Lee $\cdot$ M. Staton $\cdot$ P. Zheng $\cdot$ \\ S. Ficklin • I. Cho • C. Peace - K. Evans • G. Volk • \\ N. Oraguzie • C. Chen • M. Olmstead • G. Gmitter Jr. • \\ A. G. Abbott
}

Published online: 1 July 2012

(C) Springer-Verlag 2012

\section{Erratum to: Tree Genetics \& Genomes (2012) 8:549-557} DOI 10.1007/s11295-012-0494-7

Unfortunately, the original version of this article inadvertently misspelled the name of Dr. Margaret E. Staton as "Stanton".

The online version of the original article can be found at http://dx.oi.org/ 10.1007/s11295-012-0494-7.

J. L. Wegrzyn $(\bowtie) \cdot$ B. Figueroa $\cdot$ M. Choi $\cdot$ J. Yu $\cdot$ D. B. Neale Department of Plant Sciences, University of California at Davis, Mail Stop 4,

Davis, CA 95616, USA

e-mail: jlwegrzyn@ucdavis.edu

D. Main $(\varangle) \cdot$ S. Jung $\cdot$ T. Lee $\cdot$ P. Zheng $\cdot$ S. Ficklin $\cdot$ C. Peace $\cdot$

K. Evans $\cdot$ N. Oraguzie

Department of Horticulture and Landscape Architecture,

Washington State University,

PO Box 646414, Pullman, WA 99164, USA

e-mail: dorrie@wsu.edu

I. Cho

Department of Computer Science,

Saginaw Valley State University,

Saginaw, MI 48710, USA

\section{Staton}

Clemson University Genomics Institute, Clemson University,

Clemson, SC 29634, USA
G. Volk

National Center for Genetic Resources Preservation, USDA/ARS, Fort Collins, CO 80521, USA

M. Olmstead

Horticultural Sciences Department-IFAS, University of Florida, Gainesville, FL 32611, USA

C. Chen $\cdot$ G. Gmitter Jr.

Citrus Research and Education Center, University of Florida, Lake Alfred, FL 33850, USA

\section{A. G. Abbott}

Department of Genetics and Biochemistry, Clemson University, Clemson, SC 29634, USA 